\title{
Child-feeding strategies of African American women according to stage of change for fruit and vegetable consumption
}

\author{
Kathy Reimer ${ }^{1}$, Chery Smith ${ }^{1, *}$, Marla Reicks ${ }^{1}$, Helen Henry ${ }^{1}$, Ruth Thomas ${ }^{2}$ and \\ Janine Atwell ${ }^{2}$ \\ 'University of Minnesota, Department of Food Science and Nutrition, 1334 Eckles Avenue, St. Paul, MN 55108, \\ USA: ${ }^{2}$ University of Minnesota, Department of Work, Community and Family Education, 325 Votech, 1954 Buford \\ Avenue, St. Paul, MN 55108, USA
}

Submitted 1 April 2003: Accepted 10 October 2003

\begin{abstract}
Objective: To examine the relationship between child-feeding strategies and the stage of change for fruit and vegetable consumption of low-income African American women.

Design: Mothers were asked to think aloud as they shopped for groceries and prepared a meal for their family. Verbalisations were audio-taped and transcribed. Transcripts were coded. Coded segments were sorted according to stage of change of the women who made the verbalisation. Themes were identified and analysed for differences across the stages of change. Child-feeding strategies and factors influencing provision of fruits and vegetables to children were identified through content analysis procedures.

Setting/subjects: Seventy women, aged 18 to 45 years, were classified by stage of change (10 to 18 per stage) based on self-reported intakes of fruits and vegetables and intention to increase intake. Women on average had two to three children less than 12 years of age and tended to be single heads of households, with about half having some college or technical training.

Results: According to the women's comments, food preferences of children were important considerations for women in all stages regarding their food choice behaviours. Women in the later stages reported using more positive child-feeding strategies to promote the intake of fruit and vegetables, including positive rolemodelling and methods related to food purchasing, preparation and meal planning. Conclusions: Promoting mothers' movement to more advanced stages of change for fruit and vegetable intake may result in the use of more positive child-feeding strategies and therefore contribute to increased fruit and vegetable intake by children.
\end{abstract}

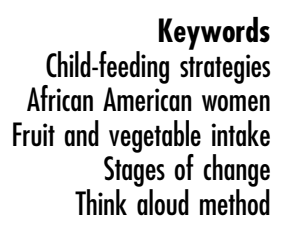

Keywords

Child-feeding strategies African American women Stages of Think aloud method
Recent epidemiological studies have shown a correlation between greater fruit and vegetable intake and reduced incidence of cardiovascular disease, cancer and diabetes, and mortality rates due to these diseases ${ }^{1-4}$. Behavioural risk factor surveillance survey data show a significant racial disparity in mortality rates from these chronic diseases. Compared with whites, heart disease, cancer, stroke and diabetes mortality rates are 29\%, 27\%, 40\% and $135 \%$ higher for African Americans, respectively ${ }^{5}$. In spite of the known benefits of fruit and vegetable intake, national dietary intake data show that the daily intake of fruits and vegetables among African American adults and children is lower than the recommended 5 servings a day ${ }^{6}$.

Parents can influence their children's food choice behaviour through the physical and social environment they provide. Physical influences include making fruits and vegetables available and accessible, and offering them to children $^{7-9}$. Social influences involve parental behaviours and beliefs such as modelling intake ${ }^{9-12}$ and the use of child-feeding strategies ${ }^{12-18}$.

Recent studies have suggested that child-feeding strategies, through restriction of foods or pressuring children to eat, may play a role in determining children's food choices ${ }^{12,16,17}$. These strategies reflect a more negative interaction with children involving commands and higher levels of control. Restricting access to certain foods increased the desire for those foods and increased their intake by children when parents were not around to monitor their intake ${ }^{19}$. Pressuring children to eat vegetables decreased their preference for them ${ }^{12,17}$. Studies have shown that when children are encouraged to eat a food by offering them some type of reward, there is a negative shift in preference for that food ${ }^{20}$. On the other hand, increased preferences for a food are noted 
when it is used as a reward for good behaviour ${ }^{21}$. Based on these results, the authors suggested that rewarding children for eating vegetables by giving them a dessert may increase their preference for the dessert and decrease their preference for the vegetable ${ }^{20,22}$.

Children tend to model the eating habits of parents and adults in their social environment ${ }^{23}$. Several studies have examined parental role-modelling and fruit and vegetable intake by children ${ }^{12,21,22}$. Fisher et $_{\text {al }}{ }^{12}$ showed that a child's fruit and vegetable intake was closely related to their parents' intake, demonstrating the importance of parental modelling. When parent's intake was low, there was increased pressure for children to eat fruits and vegetables. African American children were more likely to try fruits and vegetables when they saw their parents eat and enjoy fruits and vegetables ${ }^{24}$. In a preliminary study that investigated stage of change for healthy dietary habits, children of parents in the early stages of change experienced less positive parental modelling ${ }^{25}$.

Studies have demonstrated the importance of availability and accessibility on children's fruit and vegetable intake. In a study involving third-grade students and their parents, Hearn et al. ${ }^{7}$ found that with increased availability and accessibility of fruits and vegetables, there was increased total fruit and vegetable intake by the children when analysed in both the home and the school setting. Fruit and vegetable intake was also positively associated with availability in a study by the National Cancer Institute involving fourth-grade students and their parents ${ }^{8}$.

The Transtheoretical Model has been used to explain many health and dietary behaviours ${ }^{26-29}$. According to this model, behaviour change involves a process defined by five stages of change. In the earlier stages of precontemplation, contemplation and preparation, individuals are either not interested in changing behaviour, anticipating making a change or are actively seeking the change. In the later stages of action and maintenance, individuals have made or maintained changes in the target behaviour. Significant differences in intake of fruit and vegetables and psychosocial determinants such as knowledge, self-efficacy and social support have been noted when comparing those in the later stages with those in the early stages ${ }^{30-32}$.

To date, few studies have examined the effect that maternal stage of change has on physical and social influences regarding fruit and vegetable intake of children. The purpose of this study was to explore the potential relationship between child-feeding strategies and stage of change using a novel qualitative technique known as the think aloud method ${ }^{33,34}$. Using this method, participants were asked to verbalise all thoughts concurrent with the task of selecting groceries in a supermarket and preparing a meal at home. It is thought that this method can produce a more accurate representation of important factors considered when decisions are made.

\section{Methods}

Investigators recruited low-income African American women aged 18 to 45 years, with children under the age of 12 years $(n=70)$, through the Supplemental Food Program for Women, Infants, and Children (WIC) clinics, radio interviews, newspaper ads and by word of mouth. Low income was defined as qualifying for some type of public assistance programme, i.e. WIC, Food Stamp Program, Expanded Food and Nutrition Education Program (EFNEP), food shelves, or having a child eligible for free or reduced priced school meals. Women were required to have been born in the USA or have lived there for at least 15 years. Women were screened to recruit 1018 women in each stage of change for fruit and vegetable consumption. A food-frequency questionnaire developed by Thompson et $a l .{ }^{35}$ was used to estimate fruit and vegetable intake. Participants were asked 10 questions about how often in the last month they had eaten fruit and vegetable items (100\% juice, fruit, lettuce salad, fried potatoes, white potatoes other than fried, cooked dried beans, other vegetables, dishes with tomato sauce, vegetable soups and other mixtures that included vegetables) and how much they typically ate of these items when they ate them. Based on estimated intake, the staging algorithm involved asking women about their intention to increase their fruit and vegetable intake to at least 5 servings a day ${ }^{36}$. The study was approved by the University of Minnesota's Institutional Review Board Human Subjects Protection Committee. Women were compensated for their participation in the study with gift certificates to grocery stores.

A total of 138 verbalisation interviews were conducted in two settings, a grocery store of the participant's preference $(n=70)$ and the participant's home $(n=68)$ (two women who completed data collection in the grocery store could not be reached for the home portion). Data collection and analysis procedures for each setting were developed in a pilot test situation with 12 women using the think aloud method as described by Ericsson and Simon ${ }^{33,34}$. Protocols outlining procedures have been described elsewhere ${ }^{37}$. All verbalisations and responses to questions were audio-taped inconspicuously with a lapel microphone attached to a small recording device that was hung in a purse around the participant's neck or waist.

Prior to data collection in the grocery store, women were asked questions about usual shopping habits, including frequency of shopping with children. They were instructed to shop in for groceries for their family in their typical manner, shopping for enough to last a week. The researcher accompanied them throughout the store. They were asked to think aloud as they shopped and to say everything that came to their mind. To minimise interruptions in the thought processes of the women, investigators simply walked alongside them without communicating, except to offer non-leading probes such 
as 'What are you thinking?' or 'Can you say more about that?' Probing procedures were the same for all women, being used when there was a pause in the woman's verbalisation or to encourage continued verbalisation about a particular item.

Following the grocery store experience, participants prepared a routine meal for their family in their home with a researcher present. Preliminary questions were asked regarding their child's involvement in meal preparation. Participants were then asked to think aloud as they prepared the meal. After the meal was prepared, several general questions were asked regarding eating habits, such as 'Can you describe the eating habits for yourself and your family?'

Audio tapes were transcribed verbatim. Comments by women within each stage of change regarding childfeeding strategies were examined systematically. All segments of text pertaining to fruit and vegetables were identified and encoded according to common factors that emerged from the data influencing purchase and preparation decisions in the context of feeding children. Coding was done independently by two investigators and differences were reconciled before data were entered using the database program Filemaker Pro 5. Data were sorted according to codes and stage of change, and then a pair of investigators identified common themes using content analysis procedures ${ }^{38}$. Quotes representative of the themes were identified and themes and quotes were brought back to the research team for confirmation.

Demographic data were analysed for differences by stage of change using analysis of variance procedures (Statistical Analysis System; SAS Institute, Cary, NC, USA). Statistically significant differences $(P<0.05)$ were evaluated to determine mean differences using Duncan's multiple range test.

\section{Results}

The mean age of the women was 32 years (range 18 to 45 years) and there was a mean of 2.4 children per household (Table 1). Half worked outside the home; $51 \%$ had some college or technical training; and $60 \%$ were heads of

Table 1 Demographic characteristics of women in the study. Values are expressed as mean \pm standard deviation

\begin{tabular}{lc}
\hline & $\begin{array}{c}\text { All participants } \\
(n=70)\end{array}$ \\
\hline Age (years) & $32 \pm 7$ \\
Education* $^{*}$ & $3.4 \pm 0.9$ \\
Work outside the home $\dagger$ & $0.51 \pm 0.50$ \\
Number of children in the home & $2.4 \pm 1.4$ \\
Participation in WIC $\neq$ & $0.42 \pm 0.50$ \\
Number of adults in the home & $1.4 \pm 0.7$ \\
\hline
\end{tabular}

*Education level: 1 - 8th grade, 2 - some high school, 3 - high school graduate, 4 - some college or technical training, 5 - college graduate. † Work outside the home: no - 0, yes -1 .

$\ddagger$ Participation in the Supplemental Food Program for Women, Infants, and Children (WIC): 0 - non-participation, 1 - participation. households. There were no differences by stage of change for any demographic variables. Mean fruit and vegetable intake was directly related to stage, as it was the basis for staging (Table 2). There were high levels of juice intake by women in the later stages.

Trends were noted in the number of comments and complexity of strategies used, and in some situations differed according to stage of change. Several common themes were identified in relation to physical and social influences of parents over children's fruit and vegetable intake. Children's food preferences and the relationship between food and the health of their children were considerations for mothers. Mothers reported using various strategies to influence their children's eating habits. Based on the content, frequency and nature of the verbalisations, it was possible to attribute general characteristics of these strategies to women in different stages of change.

\section{Food preferences of children}

Food preferences of their children were major factors for most women in determining the type, form, quality and quantity of fruit and vegetables purchased in the grocery store and incorporated into meals prepared in the home. According to comments made by the women, they responded to child preferences by buying and serving what children wanted. As one mother said, 'I like to buy the vegetables that they like, like green beans or corn or broccoli... I have to buy stuff that they have a taste for.' Another said, 'Those are things' that they'll eat, so that's what's usually offered.'

Women in all stages of change made many comments about the fruits and vegetables that children liked or disliked; however, in the later stages of preparation, action and maintenance, women verbalised that there were more fruits and vegetables that were liked by children. For example, one mother said: 'And I know the kids love vegetables and that's something I always fix with my tacos.' Foods were purchased in keeping with child preferences to avoid waste and save money. One mother remarked: 'I don't know, I try to always cook things that are compatible with them [the children] also. That way I won't be wasting. I don't have money to buy extra groceries.'

\section{Nutrition and bealth concerns}

The women reported that having children made them more aware of their own eating habits, reinforcing the need to eat healthier and incorporate more fruits and vegetables in their family's diet. More women in the later stages made comments about fruit and vegetables being healthy alternatives to high-fat foods, fast foods and junk foods. One woman stated: 'Having kids myself makes me realise that I wasn't eating enough green vegetables and I am anaemic and 'ya know my kids constantly have low iron.' All women made many comments regarding their 
Table 2 Fruit and vegetable daily servings by stage of change. Values are expressed as mean \pm standard deviation*

\begin{tabular}{|c|c|c|c|c|c|c|c|}
\hline & $\begin{array}{l}\text { All women } \\
(n=70)\end{array}$ & $\begin{array}{l}\text { Pre-contemplation } \\
\qquad(n=13) \dagger\end{array}$ & $\begin{array}{l}\text { Contemplation } \\
\quad(n=10) \dagger\end{array}$ & $\begin{array}{l}\text { Preparation } \\
\quad(n=18)\end{array}$ & $\begin{array}{l}\text { Action } \\
(n=14)\end{array}$ & $\begin{array}{l}\text { Maintenance } \\
\quad(n=15)\end{array}$ & $\begin{array}{c}P \text {-value } \\
\text { (ANOVA) }\end{array}$ \\
\hline Juice & $1.9 \pm 2.1$ & $0.6 \pm 0.8^{\mathrm{a}}$ & $0.7 \pm 0.7^{a}$ & $1.2 \pm 0.8^{\mathrm{a}}$ & $3.6 \pm 2.7^{b}$ & $3.5 \pm 2.2^{b}$ & 0.0001 \\
\hline Fruit & $1.1 \pm 1.6$ & $0.4 \pm 0.4^{\mathrm{a}}$ & $0.5 \pm 0.6^{a}$ & $0.6 \pm 0.5^{\mathrm{a}}$ & $2.2 \pm 2.5^{\mathrm{b}}$ & $1.8 \pm 1.7^{\mathrm{b}}$ & 0.0035 \\
\hline Vegetables & $2.9 \pm 2.1$ & $1.7 \pm 1.2^{\mathrm{a}}$ & $1.7 \pm 0.8^{\mathrm{a}}$ & $2.5 \pm 1.0^{\mathrm{a}}$ & $4.4 \pm 3.1^{\mathrm{b}}$ & $4.2 \pm 2.1^{\mathrm{b}}$ & 0.0002 \\
\hline Fruit/juice/vegetables & $5.9 \pm 3.8$ & $2.7 \pm 1.4^{a}$ & $2.9 \pm 1.1^{a}$ & $4.2 \pm 0.8^{\mathrm{a}}$ & $9.9 \pm 3.5^{b}$ & $9.4 \pm 2.7^{\mathrm{b}}$ & 0.0001 \\
\hline Fruit/vegetables (without juice) & $4.0 \pm 2.8$ & $2.1 \pm 1.2^{\mathrm{a}}$ & $2.3 \pm 1.0^{a}$ & $3.0 \pm 1.1^{\mathrm{a}}$ & $6.6 \pm 3.8^{b}$ & $5.9 \pm 2.4^{b}$ & 0.0001 \\
\hline
\end{tabular}

ANOVA - analysis of variance.

${ }^{*}$ Means with different superscripts are significantly different $(P<0.05)$

$\dagger$ One person from this stage did not participate in the home study.

children's current weight or potential weight concerns. Representative quotes included: 'Recently my daughter went to a doctor's appointment, the baby, and they said she was thirty pounds, and I was just like, oh, my goodness. That's why my arms were killing me' and 'I do want to see them grow up and be adults ... feel good and not be weighed down with a whole lot of weight.'

Health concerns were verbalised more often by women in the later stages of change. These concerns pertained to both current and potential health issues for their children and intergenerational health concerns related to low intake of fruit and vegetables. One woman said, 'I kind of stay away from sweets, because she has done a lot of damage to her teeth with the sugar... I will let her have sweet snacks, but I prefer to let her have fruit.' Another was quoted as saying, 'I started hearing my doctor talking about diabetes and heart disease... I didn't want my kids to have to go through that kind of stuff, so I figured, get rid of it now and eat a little bit better and live a few more years.'

General comments about the nutritional quality of food were verbalised mainly by women in the later stages. These included such quotes as 'Basically the juice is for him. It is good, it is a quick snack, instead of giving him like a soda or Kool-aid, this is like 100\% fruit juice, so that would be good for him' and 'What I like is the V-8 Splash... This is our favourite kind of juice, 'cause it has all the vitamins in it that they need for a whole day with calcium.'

\section{Child-feeding strategies}

Verbalisations by women in the intermediate and later stages of change occurred with greater frequency regarding methods used to increase fruit and vegetable intake for their children, which involved food acquisition, food preparation and meal planning (Table 3). Women reported that common acquisition strategies involved practices that affected availability, like buying and keeping fruit and vegetables on hand for snacks. Food preparation strategies included adding vegetables to dishes, hiding vegetables in dishes and adding something to enhance liking for fruits and vegetables, such as cheese sauce or seasonings. Meal planning strategies involved including fruits and vegetables in lunches, replacing junk food with fruits and vegetables, and adding vegetables to meals to provide at least one vegetable. Generally, women in the later stages verbalised that they used these strategies more often than did women in the earlier stages. Few or no women in the early stages made comments such as providing balanced meals, adding vegetables to mixed dishes, etc., whereas many did in the later stages. A notable exception was that of hiding vegetables in dishes, which was more commonly mentioned by women in the preparation stage. Mothers in the preparation stage tended to 'sneak' vegetables into dishes, hoping that the children would not realise that they were eating them, in an effort to increase their children's vegetable intake.

\section{Modelling}

Grocery shopping and home meal preparation provide two opportunities for parents to model attitudes and behaviours, and to share knowledge about fruits and vegetables with their children, either positively or negatively. The majority of mothers indicated that they usually shopped with their children, mainly because they did not have childcare. In situations where mothers did not take their children with them, often it was because the children were too active, as illustrated by the following: 'She will be in one of the aisles and be taking the stuff off the shelves and get on the shelves and be hiding from me, so I try not to take her because of that.' Verbalisations indicated that only a small proportion of mothers used grocery shopping as an opportunity to teach their children about the purchase of healthy foods. As one woman said, 'Oh no, uh-uh, potato chips, no chips, nope, uh-uh, no chips... remember what I said to you that chips are not very healthy.' More women in the later stages commented about their children assisting them with food preparation, involving them in age-appropriate activities, such as washing greens or cutting vegetables. A comment reflective of this is 'Making a salad or heating the ground beef... it is usually something small.' Some mothers desired that their children learn cooking skills, as illustrated by this comment: 'She is old enough where she can participate. I like for her to do that because it helps her, gives her skills, something for her future also.'

Mothers tended to model intake of fruit and vegetables in a positive or negative manner. Positive modelling was 


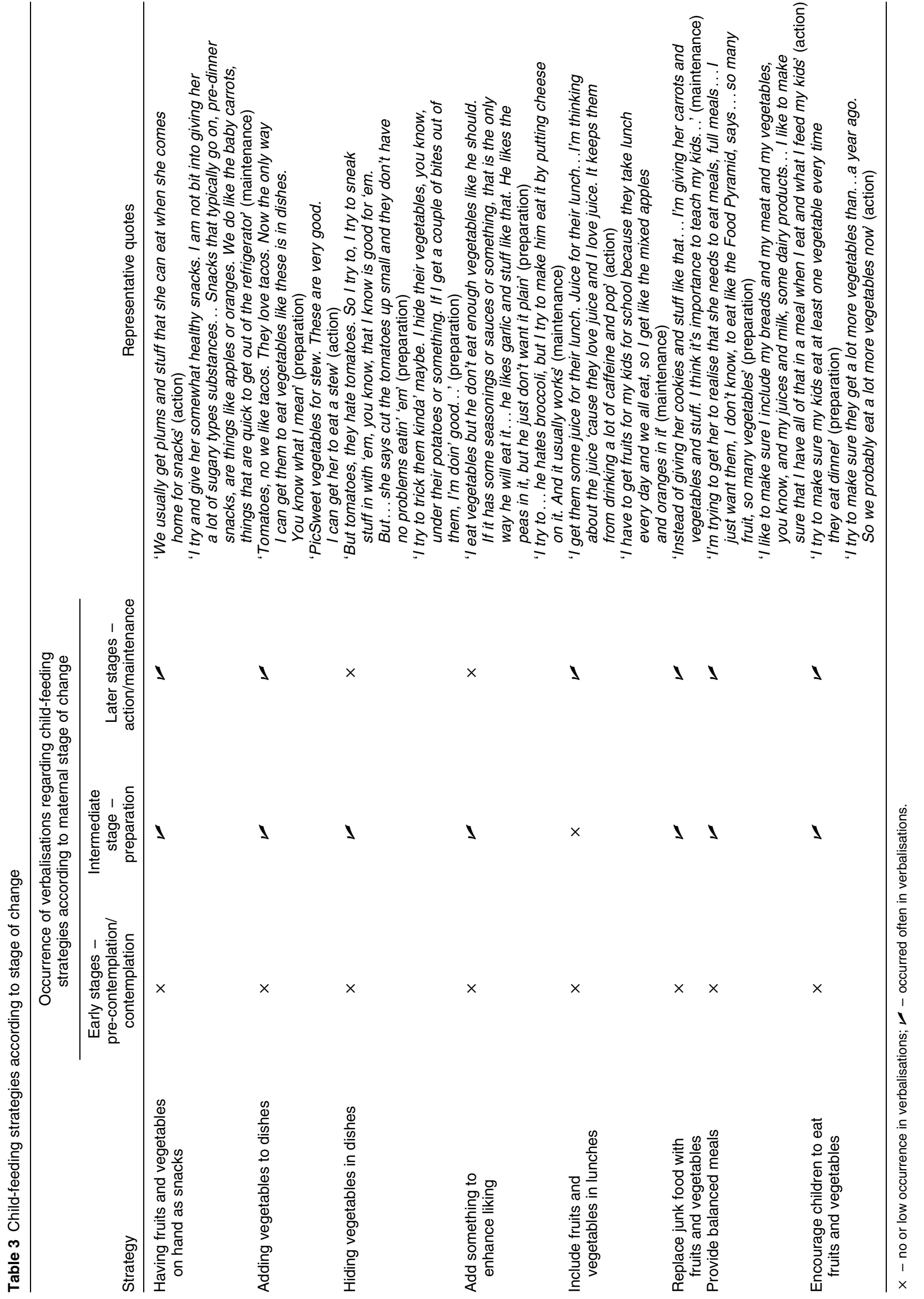


evident when mothers verbalised that they ate fruits and vegetables themselves and indicated that it was important that they set an example for their children. They also indicated that it was important to teach children to include fruit and vegetables in their diet. Negative role-modelling and influence was characterised by not eating healthy foods themselves, and therefore not modelling healthy behaviour to their children. Verbalisations suggested that some mothers were not concerned that they provide fruit and vegetables in meals for their children. More comments about positive modelling and teaching approaches were heard from women in the later stages; for example, 'I don't like green peas and beans personally... But my kids need them so I have tried to be a big girl and eat some too' and 'I found that if I overcook the broccoli I am taking vitamins out of the broccoli... They know because they read the books or they have seen little things laying around that say if you cook them in too much hot water you are taking vitamins away from it. So, a lot of it is just educating them.'

Examples of negative modelling and influence were verbalised more often by women in the early stages. One participant verbalised the following: 'But the other kids they'll eat the fruit.... and, but they won't eat tomatoes or too much of the string beans or maybe the broccoli or the cauliflower - they won't eat. So, I guess they got that from me.' Another quote represented an attitude of ambivalence relative to her children eating fruits and vegetables, 'They don't eat like a lot of fruit or vegetables and they probably eat fatty foods maybe 'cause we fry a lot of our foods. So, it's always the same things 'cause those are things that they'll eat.'

Women in the preparation stage more often verbalised a 'do as I say, not as I do' approach to child feeding. A comment representing this theme was 'I cook healthy for them, but I won't eat it. Like if "monkey see-monkey do". If they see that I am not eating it then they don't want to eat it. I have a struggle with "You're gonna eat your vegetables". I have a child that has said to me, "You're not eating, why should I eat it? What's the matter with it?" and I just need to eat what I cook.' Another participant said, 'I just haven't ate fruit as much, but I... 100\% encourage my son to... eat fruits and vegetables.'

\section{Discussion}

The results of this study, based on verbalisations of the participants, show that low-income women influenced their children's intake of fruit and vegetables in a number of ways, which differed according to their stage of change for fruit and vegetable intake. Influence was through physical means, as previously demonstrated by Cullen et $a l^{9}$, and through social means. Mothers reported that they influenced their children's intake of fruit and vegetables through physical means by increasing availability in the household through food acquisition, preparation and meal planning. Increased consumption levels were further reinforced through social factors such as modelling of normative behaviours, forms of encouragement and the use of various child-feeding strategies. The data also suggest that the presence of children in the household may act as a catalyst to influence the fruit and vegetable purchasing behaviour of women in the later stages of change.

The dynamics among mother, child and the environment were observed frequently, as all mothers identified their children's food preferences as a major factor in determining which fruits and vegetables were purchased and prepared. However, mothers in the later stages of change with a higher intake of fruit and vegetables verbalised more frequently that their children liked fruits and vegetables. This may reflect that children in homes where mothers have a higher intake have more exposure to fruits and vegetables, suggesting that environmental exposure can result in increasing or shifting of food preferences in children. Previous studies have shown that greater exposure to various foods increases a child's preference for these foods ${ }^{39}$.

Women in the later stages verbalised more food acquisition, meal planning and preparation strategies to increase fruit and vegetable consumption by their children. This would support other studies that demonstrate that making fruits and vegetables available and accessible is likely to increase intake by both parents and children $^{7,8,40}$.

Several strategies verbalised by women in later stages represented a concern that children should eat healthy foods, but did not indicate that mothers forced their children to eat fruit and vegetables. Forcing children to eat fruit and vegetables that may be healthy for them may be counterproductive $^{12,13}$ and may interfere with development of the child's self-control ${ }^{41}$. Sneaking vegetables into mixed dishes was another method used by mothers primarily in the preparation stage. It represents a more covert method of getting their children to eat vegetables, rather than overtly offering vegetables, as has been recommended by Birch and Fisher ${ }^{13}$ and Satter ${ }^{42}$. This strategy does not directly pressure children to eat vegetables, but it also does not reflect the recommended open communication and participatory decision-making.

In several studies, parental modelling and its effect on fruit and vegetable intake were strongly positively correlated and an indicator of fruit and vegetable intake in children ${ }^{9,10,12}$. In the current study, women in the later stages with higher intakes of fruit and vegetables verbalised the importance of positive role-modelling, thereby influencing their children's food choices.

In our study, more comments reflecting negative family behaviour influences were noted among the women in the earlier stages of change, which may decrease a child's preference for or intake of fruit and vegetables. More specifically, women in the preparation stage tended to verbalise more often a double-standard approach - 'Do as 
I say, not as I do' - when trying to get their children to eat fruit and vegetables. This is an important issue to address by education for mothers, since it was shown in another study that parents influenced children's choices of highfibre bread and milk through direct encouragement (injunctive norms) as well as by acting as models (descriptive norms) ${ }^{43}$.

Women in the early stages did not raise concerns as often about nutrition and health issues for their children. According to the Transtheoretical Model ${ }^{26}$, it may be that these women have inadequate information about diet and health relationships or they may have more barriers that result in lower intakes of fruits and vegetables for themselves as well as their children. Also, comments by women in these stages reflected more ambivalence about being a positive role model relative to eating fruits and vegetables and less effort in making sure their children have adequate fruit and vegetable intakes. Movement to more advanced stages involves processes of change that enhance level of knowledge, motivation and resolve ambivalence about change ${ }^{26}$. Others have shown that mother's nutritional knowledge was a predictor of fruit consumption while attitudes predicted both fruit and vegetable intake in their children ${ }^{44}$.

The mean fruit and vegetable intake in our study (5.9 servings) is higher than what might be expected in a lowincome black population. According to data for the Continuing Survey of Food Intakes by Individuals (19941996) ${ }^{6}$, African American women between the ages of 20 and 39 years ate an average of 4.5 fruits and vegetables a day. Daily fruit and vegetable intake for people whose household income was under $131 \%$ of the poverty level was 4.3 servings. Owing to the nature of the study, women who had high and low intakes of fruits and vegetables were purposely recruited to have a representation in each of the stages of change. Therefore, fruit and vegetable mean intake in our study may reflect a higher mean than the national average.

As with most research, the current study had its limitations. Because this study used qualitative research methods with African American mothers, the sample size is relatively small and therefore the results may not be applicable to the general population. Qualitative methods are labour-intensive and expensive to conduct; however, they provide rich, in-depth information that is not always captured through quantitative methods. Although the women were advised that we desired to observe a typical food purchasing and home meal preparation experience, the presence of the investigator may have altered the food purchasing and meal preparation habits of the participants. The thoughts verbalised by the women may also reflect socially desirable comments, although trained investigators emphasised the importance of saying 'whatever was on their mind'. Also, the nature of the study may have attracted participants who tend to be extroverts, and not internal processors, those who might be more comfortable volunteering for a study of this nature. However, the lengths of the transcripts reflect a variety of verbalisation tendencies.

\section{Future direction}

Efforts to increase fruit and vegetable consumption in children are more effective when they are more intensive and involve parent change and the family ${ }^{45-47}$. Given the results of the current study, it is important to educate mothers in the earlier stages of change not only about how to increase fruit and vegetable intake for their children but also for themselves. Efforts to increase their own intake will result in more positive role-modelling and childfeeding strategies for their children relative to fruit and vegetable intake. Positive child-feeding strategies should be encouraged for women in the earlier stages of change because women in the later stages tended to verbalise using strategies that research has shown to encourage fruit and vegetable intake in children. Further quantitative research will be done to test the hypotheses generated by this qualitative study.

\section{Acknowledgement}

This study was funded by USDA-CSREES 00-35200-9064.

\section{References}

1 Bazzano LA, He J, Ogden LG, Loria CM, Vupputuri S, Myers $\mathrm{L}$, et al. Fruit and vegetable intake and risk of cardiovascular disease in US adults: the first National Health and Nutrition Examination Survey Epidemiologic Follow-up Study. American Journal of Clinical Nutrition 2002; 76: 93-9.

2 Steinmetz KA, Potter JD. Vegetables, fruit, and cancer prevention: a review. Journal of the American Dietetic Association 1996; 96(10): 1027-35.

3 Van't Veer P, Jansen MC, Klerk M, Kok FJ. Fruits and vegetables in the prevention of cancer and cardiovascular disease. Public Health Nutrition 2000; 3(1): 103-7.

4 Ford ES, Mokdad AH. Fruit and vegetable consumption and diabetes mellitus incidence among US adults. Preventive Medicine 2001; 32(1): 33-9.

5 Centers for Disease Control and Prevention, National Center for Chronic Disease Prevention and Health Promotion. Behavioral Risk Factor Surveillance Survey - 1999 [online]. Available at http://www.cdc.gov/nccdphp/burdenbook2002/. Accessed May 2003.

6 US Department of Agriculture (USDA), Agricultural Research Service. Pyramid Servings Data: Results from USDA's 19941996 Continuing Survey of Food Intakes of Individuals [online]. Available at http://www.barc.usda.gov/bhnrc/ foodsurvey/pdf. Accessed May 2003.

7 Hearn MD, Baranowski T, Baranowski J, Doyle C, Smith M, Lin LS, et al. Environmental influences on dietary behavior among children: availability and accessibility of fruits and vegetables enable consumption. Journal of Health Education 1998; 29(1): 26-32.

8 Kratt P, Reynolds K, Shewchuk R. The role of availability as a moderator of family fruit and vegetable consumption. Health Education E Behavior 2000; 27(4): 471-82.

9 Cullen KW, Baranowski T, Rittenberry L, Cosart C, Hebert D, de Moor C. Child-reported family and peer influences on 
fruit, juice and vegetable consumption: reliability and validity of measures. Health Education Research 2001; 16(2): $187-200$

10 Weber Cullen K, Baranowski T, Rittenberry L, Cosart C, Owens E, Hebert D, et al. Socioenvironmental influences on children's juice, fruit and vegetable consumptions as reported by parents: reliability and validity of measures. Public Health Nutrition 2000; 3(3): 345-56.

11 Cullen KW, Baranowski T, Rittenberry L, Olvera N. Socialenvironmental influences on children's diets: results from focus groups with African-, Euro- and Mexican-American children and their parents. Health Education Research 2000; 15(5): 581-90.

12 Fisher JO, Mitchell DC, Smiciklas-Wright H, Birch LL Parental influences on young girls' fruit and vegetable, micronutrient, and fat intakes. Journal of the American Dietetic Association 2002; 102(1): 58-64.

13 Birch LL, Fisher JA. Appetite and eating behavior in children. Pediatric Nutrition 1995; 42(4): 931-53.

14 Birch LL. Development of food preferences. Annual Review of Nutrition 1999; 19: 41-62.

15 Wardle J. Parental influences on children's diets. Proceedings of the Nutrition Society 1995; 54: 747-58.

16 Fisher JO, Birch LL. Restricting access to palatable foods affects children's behavioral response, food selection, and intake. American Journal of Clinical Nutrition 1999; 69 1264-72.

17 Lee Y, Mitchell DC, Smiciklas-Wright H, Birch LL. Diet quality, nutrient intake, weight status, and feeding environments of girls meeting or exceeding recommendations for total dietary fat of the American Academy of Pediatrics. Pediatrics 2001; 107(6): E95.

18 Birch LL, Fisher JO. Mothers' child-feeding practices influence daughters' eating and weight. American Journal of Clinical Nutrition 2000; 71: 1054-61.

19 Fisher JO, Birch LL. Restricting access to foods and children's eating. Appetite 1999; 32: 405-19.

20 Birch LL, Marlin DW, Rotter J. Eating as the 'means' activity in a contingency; effects on young children's food preference. Child Development 1984; 55: 431-9.

21 Birch LL, Zimmerman SI, Hind H. The influence of socialaffective context on the formation of children's food preferences. Child Development 1980; 51: 856-61.

22 Birch LL, Birch D, Marlin DW, Kramer L. Effects of instrumental consumption on children's food preference. Appetite 1982; 3: 125-34.

23 Hertzler AA. Children's food patterns - a review: family and group behavior. Journal of the American Dietetic Association 1983; 83(5): 555-60.

24 Tibbs T, Haire-Joshu D, Schechtman KB, Brownson RC, Nanney MS, Houston C, et al. The relationship between parental modeling, eating patterns, and dietary intake among African-American parents. Journal of the American Dietetic Association 2001; 101(5): 535-41.

25 Haire-Joshu D, Brownson R, Nanney MS, Houston C, Tibbs $\mathrm{T}$, Schechtman $\mathrm{K}$, et al. Stage of readiness and role modeling of dietary patterns to children by African American parents. Journal of the American Dietetic Association 1999, 99(Suppl.): A23

26 Prochaska JO, Redding CA, Evers KE. The transtheoretical model and stages of change. In: Glanz K, Lewis RM, Rimer BK, eds. Health Behavior and Health Education: Theory, Research and Practice. San Francisco, CA: Jossey-Bass, 1997; 60-84.

$27 \mathrm{Ni}$ Mhurchu C, Margetts BM, Speller VM. Applying the stages-of-change model to dietary change. Nutrition Reviews 1997; 55(1): 10-6.

28 Greene GW, Rossi SR, Rossi JS, Velicer WF, Fava JL,
Prochaska JO. Dietary applications of the stages of change model. Journal of the American Dietetic Association 1999; 99(6): 673-8.

29 Curry SJ, Kristal AR, Bowen DJ. An application of the stage model of behavior change to dietary fat reduction. Health Education Research 1992; 7(1): 97-105.

30 Campbell MK, Reynolds KD, Havas S, Curry S, Bishop D, Nicklas T, et al. Stages of change for increasing fruit and vegetable consumption among adults and young adults participating in the national 5-a-Day for Better Health community studies. Health Education \& Behavior 1999; 26(4): 513-34.

31 Campbell MK, Symons M, Demark-Wahnefried W, Polhamus $\mathrm{B}$, Bernhardt JM, McClelland JW, et al. Stages of change and psychosocial correlates of fruit and vegetable consumption among rural African-American church members. American Journal of Health Promotion 1998; 12(8): 185-91.

32 Brug J, Lechner L, de Vries H. Psychosocial determinants of fruit and vegetable consumption. Appetite 1995; 25: 285-96.

33 Ericsson KA, Simon HA. Verbal reports as data. Psychological Review 1980; 87: 215-51.

34 Ericsson KA, Simon HA. Verbal Reports as Data. Cambridge, MA: The MIT Press, 1993.

35 Thompson FE, Subar AF, Smith AF, Midthune D, Radimer KL, Kahle LL, et al. Fruit and vegetable assessment: performance of 2 new short instruments and a food frequency questionnaire. Journal of the American Dietetic Association 2003; 102(12): 1764-72.

36 National Institutes of Health Behavior Change Consortium website, http://www1.od.nih.gov/behaviorchange/ measures/PDF/5daysstg.pdf.

37 Reicks M, Smith C, Henry H, Reimer K, Atwell J, Thomas R. Use of the think aloud method to examine fruit and vegetable purchasing behaviors among African American low-income women. Journal of Nutrition Education and Behavior 2003; 35: 154-60.

38 Miles MN, Huberman AM. Qualitative Data Analysis, 2nd ed. Thousand Oaks, CA: Sage Publications, 1994.

39 Birch LL, Marlin DW. I don't like it; I never tried it: effects of exposure on two-year-old children's food preferences. Appetite 1982; 3: 353-60.

40 Crockett JS, Sims LS. Environmental influences on children's eating. Journal of Nutrition Education 1995; 27: 235-49.

41 Costanzo PR, Woody EZ. Domain-specific parenting styles and their impact on the child's development of particular deviance: the example of obesity proneness. Journal of Social and Clinical Psychology 1985; 3(4): 425-45.

42 Satter E. How to Get Your Kid to Eat... But Not Too Much. Palo Alto, CA: Bull Publishing Company, 1987.

43 Berg C, Jonsson I, Conner M. Understanding choice of milk and bread for breakfast among Swedish children aged 11-15 years: an application of the Theory of Planned Behavior. Appetite 2000; 34: 5-19.

44 Gibson EL, Wardle J, Watts CJ. Fruit and vegetable consumption, nutritional knowledge and beliefs in mothers and children. Appetite 1998; 31: 205-28.

45 Epstein LH, Gordy CC, Raynor HA, Beddome M, Kilanowski CK, Paluch R. Increasing fruit and vegetable intake and decreasing fat and sugar intake in families at risk for childhood obesity. Obesity Research 2001; 9(3): 171-8.

46 Cilaska D, Miles E, O'Brien MA, Turl C, Tomasik HH, Donovan $\mathrm{U}$, et al. Effectiveness of community-based interventions to increase fruit and vegetable consumption. Journal of Nutrition Education 2000; 32(6): 341-52.

47 Wardle J, Cooke LJ, Gibson EL, Sapochnik M, Sheiham A, Lawson M. Increasing children's acceptance of vegetables; a randomized trial of parent-led exposure. Appetite 2003; $\mathbf{4 0}$ $155-62$. 